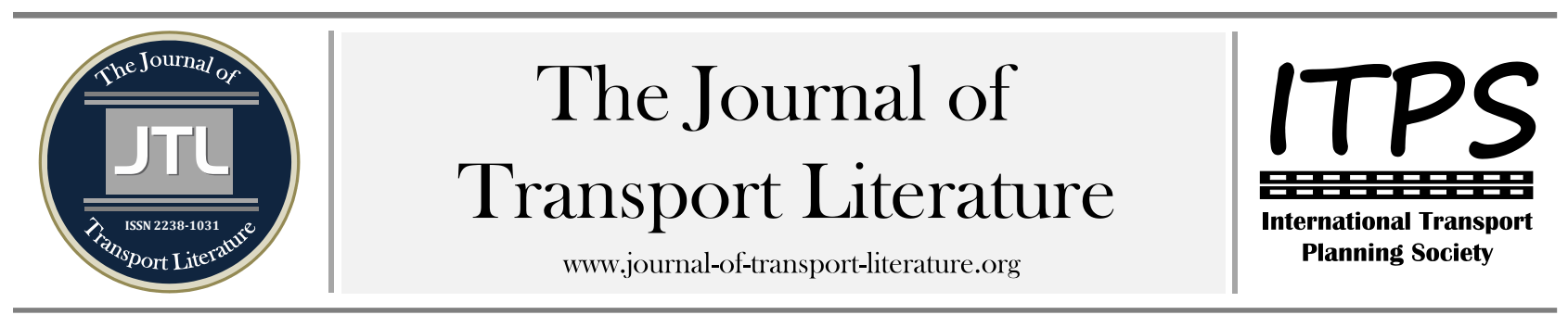

\title{
Uncracked joints in plain concrete pavements: causes, effects and possibilities of improvements
}

Mauricio Pradena ${ }^{1,+} ;$ Lambert Houben ${ }^{2}$

${ }^{1}$ Civil Engineering Department-Universidad de Concepción, Concepción, Chile

1,2 Section Pavement Engineering-Delft University of Technology, Delft, The Netherlands

\section{Article Info}

Keywords:

pavements

concrete

uncracked

joints

crack width

Submitted 23 Jan 2015;

received in revised form 22 May

2015; accepted 12 Jul 2015

Licensed under

Creative Commons

CC-BY 3.0 BR.

\begin{abstract}
During the construction of Jointed Plain Concrete Pavements (JPCPs) in Chile, it was observed that joints remained uncracked. The objectives of this paper are to evaluate the effects of uncracked joints (UnCrJ) in JPCPs and to propose possible solutions or improvements to avoid or minimize this phenomenon. Considering low thermal amplitude as cause of UnCrJ, a rational-based, detailed and empirically validated model is used to predict UnCrJ and crack width. The modelled results are not only due to material changes but also to the location of the series of cracks in time in the JPCP system. The paper contributes with this rational approach, instead of an empirical-simplified one, to achieve the objectives. For the modelled conditions, the "as-built" slab length range is $8 \mathrm{~m}$ to $56 \mathrm{~m}$ instead of the $4 \mathrm{~m}$ designed one. Then, more curling, joint faulting, water infiltration in sealed joints and load transfer efficiency $\leq 70 \%$ are expected. The alternative solutions proposed are associated to innovations as short joints spacing, unsealed joints and saw-cuts up to $50 \%$ thickness made with thin blade $(\leq 3 \mathrm{~mm})$, which was verified with new field evidence provided in the article.
\end{abstract}

+ Corresponding author. Stevinweg 12628 CN Delft, the Netherlands.

E-mail address: m.a.pradenamiquel@tudelft.nl.

\section{Introduction}

The objectives of the present paper are to evaluate the effects of the UnCrJ in JPCPs and to propose possible solutions or improvements to avoid or minimize this phenomenon.

JPCPs have joints, these are weak zones where it is expected the cracks will be produced. In fact the designed slab length considers that the joints crack. During the construction of JPCPs in winter in Chile, in presence of rain, it was observed that the joints remained uncracked even 3 weeks after construction. However, in dry conditions (summer), the cracking time of the first joints in JPCPs at the same region is less than 42 hours after the concrete placement. In effect, the rain can produce a regulation of the temperature; hence the thermal deformation is less and less potential cracks at the joints. If there are joints that remain uncracked the design hypothesises are not valid anymore, because the Effective Slab Length (EfSL) is longer than the designed one. This article deals with the questions, How UnCrJ do affect the performance of JPCPs? and, What possible solutions or improvements can be proposed to avoid or minimize this phenomenon?.

Between the few studies available about UnCrJ or freezing joints, the studies made by Lee (2003) and Lee and Stoffels (2003) are highlighted. The focus of these studies is selecting and designing joint sealants using the Lee-Stoffels model to estimate joint openings. But, the model is not applicable to new JPCPs. On the other hand, the American Association of State Highway and Transportation Officials (AASHTO) and the Mechanistic-Empirical Design Guide (MEPDG) use an empirical formula to predict of one part of the cracking process of JPCPs, the estimation of the joint opening (AASHTO 1993; NCHRP 2003). Chon and Lee (2007) studied the UnCrJ using the simplified formula of AASHTO.

The present article studies the gap between the JPCP design and the as-built JPCP, produced by construction conditions, hence new JPCPs. To determine the initiation and development of the cracking process in JPCPs, the paper contributes with a rational-based, detailed model developed by the authors and empirically validated (Pradena and Houben, 2014a; 2014b; 2015a). Particularly useful to achieve the objectives of the paper are the prediction of the UnCrJ, of course, and the crack width under the joints (joint opening) that can be related with Joint Faulting (JF) and Load Transfer Efficiency (LTE). Moreover, the article proposes innovations in JPCPs (Pradena and Houben, 2015b) as possible solutions or improvements to avoid or minimize the UnCrJ and their effects. Finally, the paper provides new field data to verify the technical feasibility of one of the proposed possibilities.

Section 1 describes possible causes of UnJs, particularly the one studied in this paper. In section 2 the method to determine the effects of UnCrJ and to propose solutions is described. Section 3 gives the results and analysis of the EfSL, AvCW1st and LTE. In section 4 possible solutions or improvements to avoid or minimize the effects of UnCrJ are defined. 


\section{Causes of uncracked joints}

In general, the requirements for minimum saw-cut depth are more than one-third or one-fourth of the concrete slab thickness. For instance, the MEPDG recommends a saw cut depth of one-third of the slab thickness for JPCPs placed on a permeable or stabilized base (NCHRP 2003). One possible cause of UnCrJ is a shallow saw-cut not able to generate enough weakness to the joint cracking. Other possible cause of UnCrJ is low thermal amplitude, so less restricted pavement deformation $\varepsilon(t)$, according to the Equation 1 (AASHTO, 1993) and then less internal concrete stresses. In effect, Houben determined the amplitude of the daily temperature variation (Tampday) as one of the most influential parameters of the cracking process of JPCPs (Houben, 2010a; 2010b). Low Tampday can be characteristic of the location where the JPCP is constructed, but also can occur by specific variations of the weather during the time of construction. For instance, the presence of rain can moderate the temperature variations as was the case observed in Chile. The present article considers that the requirements for minimum saw-cut depth are fulfilled, so it concentrates in the low Tampday as the cause of UnCrJ.

$$
\varepsilon(\mathrm{t})=\alpha * \Delta \mathrm{T}
$$

\section{Method to determine the effects of uncracked joints and to propose solutions}

The method to determine the effects of the UnCrJ includes the prediction of the cracking process of JPCPs using a rational model, the determination of the relation AvCW1st-LTE using the results of a 3D finite-element tool and the evaluation of the JF using equations depending of the slab length or the joint opening. This method is used as well to evaluate possibilities of solutions or improvements that include innovations in JPCPs.

\subsection{Rational model of cracking at transverse joints of JPCPs}

The prediction of the cracking process in JPCPs is a very challenging subject with numerous variables involved. Even a detailed system as MEPDG uses a simplified formula for one part of this process, i.e. the estimation of the joint opening (NCHRP 2003). In the present article the cracking process of JPCPs is predicted by a rational and detailed model developed by the authors and empirically validated using field data of JPCPs in Belgium and Chile in urban, interurban and even industrial applications (Pradena and Houben, 2014a; 2014b; 2015a). In the JPCP system modelled, the prediction of the crack width is not only the result of the material changes but also the location of the different series of cracks in time. In this way, it is possible to know the joints that remain uncracked. When there are UnCrJ, the EfSL differ of the designed slab length. The changes of the concrete since early-age are modelled by the development in time of the concrete properties, the shrinkage (according to Eurocode 2: Design of Concrete Structures - Part 1-1: General rules and rules for buildings) and the thermal deformation rather than fixed mean values as the AASHTO simplified formula (AASHTO 1993). The details of the model can be found in Houben (2010a, 2010b) and Pradena and Houben (2015a), but the basic formulation is that the occurring tensile stresses in a JPCP is product of the restricted deformation, following from Hooke's law, but affected by the viscoelastic behaviour of the concrete (relaxation) and amplidied at joints (Houben, 2010a; 2010b).

$$
\sigma(\mathrm{t})=\mathrm{g} * \mathrm{RF} * \mathrm{E}(\mathrm{t}) * \varepsilon(\mathrm{t}) \quad(\mathrm{MPa})
$$

where: $\mathrm{E}(\mathrm{t})=$ time-dependent modulus of elasticity of the concrete (MPa); $\varepsilon=$ total time-dependent JPCP tensile strain due to shrinkage and thermal effects $(-) ; R F=$ relaxation factor $(-) ; g=$ enlargement factor $(-)$.

$$
\mathrm{g}=\frac{\mathrm{h}}{\mathrm{h}-\mathrm{jd}}
$$

The greatest tensile stresses occur at joints (weakened cross-section). When the JPCPs thickness is $h$ (mm) and the sawcut depth $j d(\mathrm{~mm})$, the relative joint depth $r j d(\%)$ is:

$$
\mathrm{rjd}=\frac{\mathrm{jd}}{\mathrm{h}} * 100
$$

The tensile stresses build up over the so-called breathing length $\left(\mathrm{L}_{a 1}\right)$. This is that part of a long structure that exhibits horizontal movements due to temperature changes (or another varying influencing factor) (Houben 2010b).

$$
\mathrm{L}_{a 1}=\frac{E_{c m} * \varepsilon}{\gamma * \mathrm{f}}
$$

Where: $E_{c m}=$ average modulus of elasticity (MPa) at the moment of the crack; $\varepsilon=$ maximum obstructed deformation of the pavement (-); $\gamma=$ volume weight of concrete $(\mathrm{kN} / \mathrm{m} 3) ; \mathrm{f}=$ friction between the concrete slab and the underlying base $(-)$.

The cracks occur when the tensile stress $(\sigma)$ exceeds the tensile strength $\left(\mathrm{f}_{c t m}\right)$. Because of the initial crack width $\mathrm{W}_{1 i}$, a reduction $\Delta \sigma_{1}$ of the maximum tensile stress occurs. The spacing $L_{w 1}$ between 2 primary cracks is equal to 2 times the breathing length.

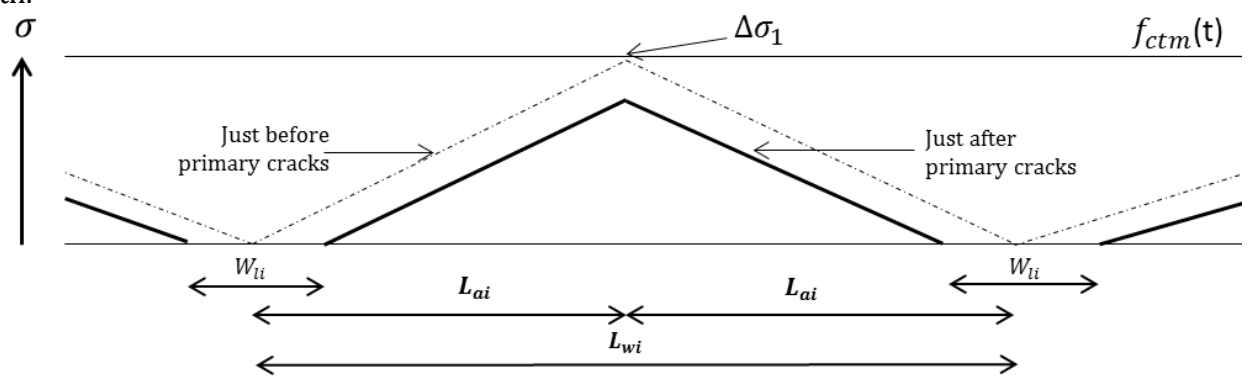

Figure 1 - Development of the tensile stresses and cracks initiation in the pavement. Source: Houben (2010a).

The coefficient of thermal expansion is modelled as a function of the modulus of elasticity and the hydration temperature as a function of time. Significant differences were found when different $R F s$ were applied to real situations of JPCPs. Accordingly, the authors proposed a new equation for the $R F$ as a function of time (Pradena and Houben, 2015a).

The rational model was developed with the objective to link the behaviour of the concrete since early age with the performance of JPCPs. Accordingly, the target outputs of the modelling since early age are trends in agreement with the reality more than exact values. For instance, values of crack width are possibly to relate with a representative LTE, i.e. the Average Crack Width of the 1st series of cracks, AvCW1st (the widest ones) after 1 year, because at that time it remains 
more or less stable during the life time of the JPCP (Houben, 2010a; 2010b). Even when simplifications have been made in the complex process of JPCPs cracking (for instance in the modelling of the temperature), the model has shown reasonably good predictions of the transversal cracking process in JPCPs (Pradena and Houben, 2014a; 2014b; 2015a).

Houben modelled the climatic conditions basically by the changes in the temperature that produce the thermal deformation of the pavement (Houben, 2010a). In the Equation 1 the thermal deformation depends of the difference in temperature between time $t$ and the time of construction of the JPCP. From this point of view the climatic conditions considered originally by Houben $(\Delta T$ in Equation 1$)$ are similar to the ones of the Chilean JPCPs where UnCrJ were observed (Pradena and Houben, 2014c). In effect, it is a coastal area, and originally Houben modelled the temperature conditions of JPCPs located in a zone with moderate sea climate (Houben, 2010b) where the daily temperature is on average at May 1 and at November 1 . The amplitude of the average daily temperature (Tampyear) is described by means of a sine-function. The daily temperature of the JPCP is estimated to be maximum about $25^{\circ} \mathrm{C}$ midsummer (August 1) and minimum about $5^{\circ} \mathrm{C}$ midwinter (February 1), referring to the northern hemisphere (Houben, 2010b). The Tampday is described by means of a sine-function that reaches its maximum at 4:00 PM, its minimum at 4:00 AM, and its average at 10:00 AM and 10:00 PM (Houben, 2010b). The specific Tampyear and Tampday considered by Houben (2010b), are the same used in this paper as the average conditions related with a moderate sea climate, i.e. Tampyear $10^{\circ} \mathrm{C}$ and Tampday $5^{\circ} \mathrm{C}$. However, sometimes there are specific variations of the weather during the time of construction of the JPCPs that affect the average conditions. For instance, the presence of rain can moderate the temperature variations as was the case observed in the JPCPs built in the Chilean winter. In effect, the possibility of rain during the construction process of JPCPs in winter is not unusual. Considering this, and the fact that this paper deals with low thermal amplitude as the cause of UnCrJ, the simulations are made with lower values of Tampday $\left(2^{\circ} \mathrm{C}, 3^{\circ} \mathrm{C}\right.$ and $\left.4^{\circ} \mathrm{C}\right)$ regarding to the average conditions of the construction in winter season. In addition, the evaluation is made over traditional JPCPs; i.e. conventional slab length ( $\geq 3.5 \mathrm{~m}$ ), saw-cutting of onefourth to one-third of the pavement thickness, and sealed joints. Moreover, undowelled joints and granular base under the concrete slabs are considered because they are critical to the production of deteriorations like JF, and because these are the conditions of the Chilean JPCPs (Pradena and Houben, 2014c). Finally, the rational-based, detailed modelling includes specific construction conditions of the JPCPs rather than general cases. In this paper, the simulations are made to JPCPs constructed in winter, at 10:00 AM, with slab length $4 \mathrm{~m}$ and RJD 25\%, 30\% and 35\%. The period of evaluation is 1 year; the concrete grade $\mathrm{C} 28 / 35$ and friction 1.

\subsection{Relation AvCW1st-LTE and evaluation of joint faulting}

The effects of the UnCrJ on the performance of the JPCPs are shown basically by the LTE and JF. The relation AvCW1st LTE is determined using the experimental validation of joint load transfer of the 3D finite-element analysis tool EverFE (Davids and Mahoney, 1999). The evaluation of the JF is shown conceptually using the equation of Yu et al (1996), with the JF as function of the slab length, and the equation of Bustos et al (2002), with the JF as function of the joint opening.

\subsection{Possible solutions or improvements}

The rational model of cracking process of JPCPs and the relation AvCW1st -LTE from the finite-element software EverFE, are used to evaluate the proposed solutions or improvements to avoid or minimize the UnCrJ and their effects. The proposals are made over traditional JPCP, innovations as JPCP-ShJS and saw-cut with thin blade ( $\leq 3 \mathrm{~mm})$ associated to unsealed joints. These innovations are described in Pradena and Houben (2015) and here only a brief summary is presented. ShJS in order to $50 \%$ of traditional JPCP slab length results in lower less slab tensile stresses because of the traffic load configuration and the reduced slab curling. This results in 70 to $100 \mathrm{~mm}$ less thickness than traditional AASHTO design (Roesler, 2013). The JPCP-ShJS include granular base with limited fines ( $\leq 8 \%$ passing $75 \mu \mathrm{m})$; thin saw-cut at joints (2-3 mm thick); no joints sealing and no dowel bars (Roesler, 2013). Certain aspects of this technology have been patented (Covarrubias, 2012).

The costs of sealing transverse contraction joints are estimated between 2 and $7 \%$ of the initial construction cost of a JPCP (Hall, 2009). And keeping the joints sealed for 10 years, cost $45 \%$ more than a JPCP with unsealed joints (Shober, 1987). However the joints seals are not working well enough, having commonly adhesive and/or cohesive failures, not keeping the joint free of water and long-term JF data shows a strong correlation with annual rainfall (Jung et al, 2011). Hence, unsealed joints with narrow saw-cut width $(\leq 3 \mathrm{~mm})$ and limited fines in the base have been proposed. This technology can be applied to JPCPs with traditional slabs or ShJS, where even they are part of the design features (Roesler, 2013). The implications of narrow saw-cutting with thin blade $(2 \mathrm{~mm})$ are investigated in 12 joints of a $180 \mathrm{~mm}$ JPCP in Chile, in similar conditions than the modelled ones. In this field experience, the saw-cut operator had not specific instruction about the RJD, more than the Chilean technical specifications of RJD 35\%.

\section{Results and analysis}

For the modelled conditions the range of EfSL values is $8 \mathrm{~m}$ to $56 \mathrm{~m}$, where in general is valid that the lower Tampday produces longer EfSL. The Equation 6 (Yu et al, 1996) is useful to clarify the influence of the EfSL, produced by UnCrJ in the JF. In Equation 6, the sign (-) represents a reduction of JF.

$$
\text { FAULTND }=f\left(C E S A L,-\frac{\mathrm{h}}{\text { JTSPACE }},-C d,- \text { BASE, FI, PRECIP, -DAYS90, -WIDENLANE }\right)
$$

where: FAULTND = mean transverse non-dowelled joint faulting (in) ; CESAL = Cumulative equivalent single axle loads (millions/lane); $\mathrm{h}=$ slab thickness (in) ; JTSPACE = mean transverse joint spacing $(\mathrm{ft}) ; \mathrm{Cd}=$ drainage coefficient of AASHTO ;

BASE $=1$ if there is stabilized base, otherwise $0 ; \mathrm{FI}=$ mean freezing index ( ${ }^{\circ} \mathrm{F}$-days $) ; \mathrm{PRECIP}=$ mean annual precipitation (in) ; DAYS90 = days with maximum temperature greater than $90^{\circ} \mathrm{F} ;$ WIDENLANE $=1$ if there is a widened traffic lane, otherwise 0.

For instance for RJD 30\%, the EfSL at Tampday $4{ }^{\circ} \mathrm{C}$ is $8 \mathrm{~m}$ and $52 \mathrm{~m}$ at Tampday $3^{\circ} \mathrm{C}$. Ceteris paribus, with the exception of the EfSL (JTSPACE in Equation 4), comparatively the JF value will be higher when the EfSL is $52 \mathrm{~m}$ than $8 \mathrm{~m}$.

In addition, because the EfSL is longer than the designed slab length of $4 \mathrm{~m}$, the effective stresses produced by the traffic and the slab curling are higher in the JPCPs in-service than the ones considered originally in the design. This situation produces deterioration of the pavement and eventually cracks in the slabs. Besides, where there are joints that remain 
uncracked, there is a waste of money and time, saw-cutting the joints, preparing the joints to receive the seal, installing the seal and dowels bars (if they are applied) at UnCrJ.

The range of AvCW1st is between $2.0 \mathrm{~mm}$ to $5.5 \mathrm{~mm}$, where in general is valid that a lower Tampday produces longer EfSL and therefore wider cracks. The Equation 7 (Bustos et al, 2002) is useful to explain the influence of the crack width at joints, related with the presence of UnJs, in the JF. In Equation 7, the sign (-) represents a reduction of JF.

$$
\Delta \mathrm{Esc}=f\left(\frac{\Delta \mathrm{ESAL}}{\text { Edad }}, \frac{\text { OPEN }}{\text { Edad }},-\mathrm{Cd}, \mathrm{DcP},- \text { EspLosa, }- \text { BAm, }- \text { Widlane }\right) \quad(\mathrm{mm})
$$

where: $\triangle \mathrm{Esc}=$ annual increment of JF in undowelled JPCP $(\mathrm{mm}) ; \Delta \mathrm{ESAL}=$ annual equivalent single axle loads (millions/lane) $;$ OPEN = joint opening $(\mathrm{mm}) ;$ Edad $=$ age of the JPCP (years) $; \mathrm{Cd}=$ drainage coefficient of AASHTO ; DcP = days of year with rainfall over $5 \mathrm{~mm}(-)$; EspLosa $=$ thickness of concrete slab $(\mathrm{mm}) ;$ BAm $=1$ if there is a tied concrete shoulder, otherwise 0 ; Widlane $=1$ if there is a widened traffic lane, otherwise 0 .

For instance for RJD 30\%, the AvCW1st at Tampday $4^{\circ} \mathrm{C}$ is $2.2 \mathrm{~mm}$ and $4.8 \mathrm{~mm}$ at Tampday $3^{\circ} \mathrm{C}$. Ceteris paribus, with the exception of the AvCW1st (OPEN in Equation 7), comparatively the JF value will be higher when the AvCW1st is $4.8 \mathrm{~mm}$ than $2.2 \mathrm{~mm}$.

In addition, wider cracks can facilitate the seal failures, that it is a sensible issue, especially considering the concerns about joint seals effectiveness. Seal failures allow the introduction of water and coarse incompressible into the joints, that can produce joint spalling. The introduction of water can drag fines from the base (pumping) affecting the support of the concrete slabs. This situation can contribute to the production of JF and cracks on the slabs.

In undowelled JPCPs, a LTE $70 \%$ or higher is generally considered appropriate to a good performance. According to the experimental validation of the joint load transfer of the finite-element software EverFE, the crack width under the joints must be $1.1 \mathrm{~mm}$ as maximum for a LTE $\geq 70 \%$ (Davids and Mahoney, 1999). As the range of AvCW1st is between $2.0 \mathrm{~mm}$ to $5.5 \mathrm{~mm}$, the LTE $<70 \%$, and low LTE contributes to JF and cracks in the slabs.

All these deteriorations affect at the end the perception of the users of the pavements. For this, the present paper pretends to draw the attention of the UnCrJ problem and to propose possible solutions or improvements.

\section{Proposal of possible solutions or improvements}

A possible of improvement is to make deeper saw-cuts. For instance, with RJD 45\% the EfSL is $4 \mathrm{~m}$ (with the exception of Tampday $2^{\circ} \mathrm{C}$ ) i.e. the JPCPs are working as they were designed. However, the AvCW1st is $1.4 \mathrm{~mm}$ and the LTE insufficient. But, according to Hansen and Jensen (2001) the LTE could be still good when strong coarse aggregates are used (this situation requires further specific investigation).

In a previous study the authors found an AvCW1st reduction of $40 \%$ when slabs with $50 \%$ length of traditional JPCPs are used (Pradena and Houben, 2014a). In this way, the LTE is $78 \%$ associated to AvCW1st $0.9 \mathrm{~mm}$ when the RJD is $45 \%$. However the EfSL is $4 \mathrm{~m}$ and not $2 \mathrm{~m}$ as the JPCP-ShJS were designed. With RJD 50\%, the values of LTE and AvCW1st are still the same as RJD 45\%, but the EfSL is $2 \mathrm{~m}$ as the JPCP-ShJS were designed.

A RJD 50\% is not difficult to reach in practice using a conventional sawer with thin blade $\leq 3 \mathrm{~mm}$, associated to unsealed joints. In fact, the 12 joints investigated in the field have RJD $\geq 50 \%$ with $72 \%$ RJD average (Examples at Figure 2). This field verification was made over a $180 \mathrm{~mm}$ thick JPCP on a local street in Chile. Hence, a RJD 50\% should be even more feasibly in JPCP-ShJS because they are thinner than the traditional JPCPs (Roesler, 2013).
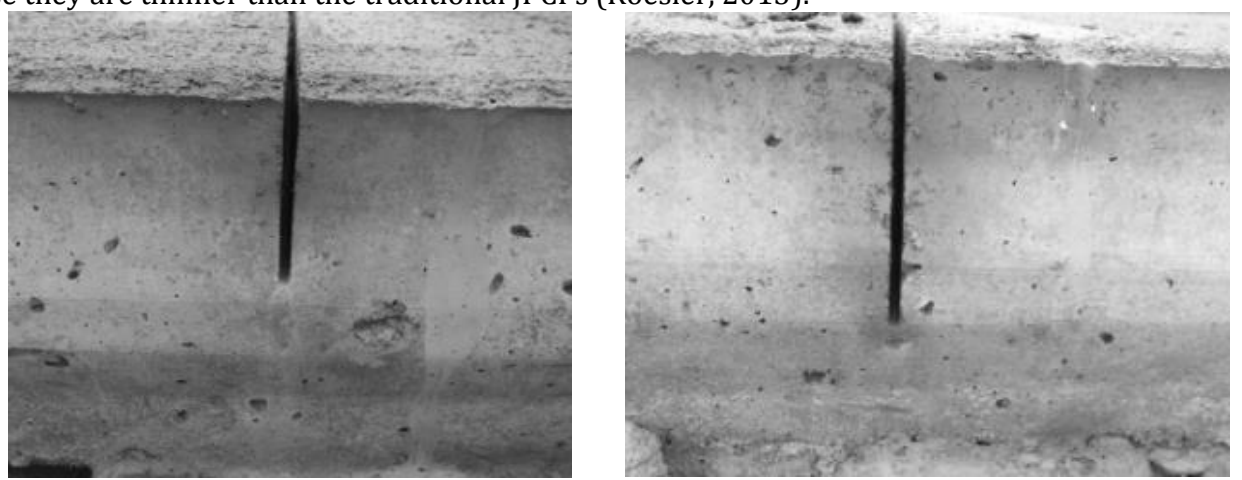

Figure 2 - Saw-cuts made with thin blade ( $2 \mathrm{~mm}$ ). Joint with RJD 50\% (left) and joint with RJD 65\% (right). Source: authors.

\section{Conclusion}

The objectives of the present paper are to evaluate the effects of the UnCrJ in JPCPs and to propose possible solutions or improvements to avoid or minimize this phenomenon.

The article contributes to the study of the gap between the JPCP design and the as-built JPCP, produced by construction conditions, hence new JPCPs. To determine the cracking process in JPCPs, the paper contributes with a rational-based, detailed model developed by the authors and empirically validated. In the JPCP system the UnCrJ and AvCW1st are not only results of material changes but also the location of the series of cracks in time. This is one of the main differences with the formulas for joint opening of AASHTO and MEPDG. Moreover the modelling includes the development in time of the concrete properties, shrinkage and thermal deformation rather than fixed mean values. Furthermore, the rational model includes specific construction conditions of the JPCP rather than general cases. In particular, the season and time of the day when the JPCPs are built (winter, at 10:00 AM), Tampyear $\left(10^{\circ} \mathrm{C}\right)$ and Tampday $\left(2^{\circ} \mathrm{C}, 3^{\circ} \mathrm{C}\right.$ and $\left.4^{\circ} \mathrm{C}\right)$, the concrete grade (C28/35), and the saw-cut depth (RJD 25\% to 50\%) in traditional JPCP (slab length $4 \mathrm{~m}$ ). In this way it is possible to conclude that the range of EfSL is $8 \mathrm{~m}$ to $56 \mathrm{~m}$, where in general is valid that the lower Tampday produces longer EfSL. And longer EfSL produces higher values of JF. Moreover higher effective stresses (than the designed ones) produced by the traffic and the slab curling are expected. Besides, where there are joints that remain uncracked, there is a waste of money 
and time, saw-cutting the joints, preparing the joints to receive the seal, installing the seal and dowels bars (if they are applied) at UnCrJ.

The range of AvCW1st is between $2.0 \mathrm{~mm}$ to $5.5 \mathrm{~mm}$, where in general is valid that a lower Tampday produces wider cracks at joints. And wider cracks produce higher values of JF. Furthermore the LTE $<70 \%$, being the limit for an expected good JPCP performance a LTE 70\% (associated to a crack width 1.1. $\mathrm{mm}$ ). The low LTE related with wider cracks can contribute to JF and cracks in the slabs as well. In addition, wider cracks can facilitate the seal failures, that it is a sensible issue, considering the concerns about joint seals effectiveness. Seal failures facilitate joint spalling, pumping and JF. All these deteriorations affect the perception of the users of the JPCPs. For this, the present paper pretends to draw the attention of the UnCrJ problem, proposing possible solutions or improvements.

A possibility of improvement is to make deeper saw-cuts. For instance with RJD 45\% the EfSL is $4 \mathrm{~m}$ (with the exception of Tampday $2^{\circ} \mathrm{C}$ ) i.e. the JPCPs are working as they were designed. However the AvCW1st is $1.4 \mathrm{~mm}$ and then the LTE < $70 \%$, so insufficient for a good performance (it could be still good if strong coarse aggregates are used, situation that requires further specific research). An innovation in JPCPs as ShJS reduces the crack width with $40 \%$, so LTE is $78 \%$ associated to a RJD $45 \%$. However the EfSL is $4 \mathrm{~m}$ and not $2 \mathrm{~m}$ as the ShJS were designed. With RJD 50\%, the LTE is still $78 \%$, but the EfSL is $2 \mathrm{~m}$ as the JPCPs-ShJS were designed.

The paper provides new field evidence that verify the technical practical feasibility to make deeper saw-cuts. In fact, the 12 joints investigated in field has RJD 50\% or more (average $72 \%$ RJD). This field verification was made over a $180 \mathrm{~mm}$ thick JPCP. Hence, a RJD 50\% should be even more feasibly in JPCP-ShJS because they are thinner JPCPs. The saw-cuts were made using conventional sawer with thin blade $(2 \mathrm{~mm})$, associated to the JPCP innovation unsealed joints.

As parts of the proposals of possible solutions or improvements are associated to JPCPs innovations, there is a limitation in the follow-up of their life-cycle. For instance, the JPCP where RJD 50\% was verified (a local street), has shown a remarkable performance after 3.5 years in-service, but there is necessary to continue the follow-up and to expand it to other experiences. Nevertheless a rational-based, empirically verified model based on the material properties and the logic of the physical cracking process at joints of JPCPs has advantage over an empirical one, because it allows more reliable extrapolations to different conditions that the empirical ones where the model was developed or validated. Finally, the effects of strong coarse aggregate over the LTE require further investigation.

\section{Acknowledgements}

The following organizations and persons are acknowledged: The International Scientific Geo-Conference SGEM and its publisher; the International Multidisciplinary Scientific Conference SGEM on Social Sciences and Arts (section Architecture and Design), and its publisher; the Service of Housing and Urbanism, Bio Bio Region, the construction companies Ebco and Ecobell and the engineers Leonardo Blumler, Ricardo Irribarra and Michael Neira.

\section{References}

AASHTO (1993). AASHTO guide for design of pavement structures.

Bustos M., de Solminihac H., Darter M. \& Covarrubias J.P. (2002) Development of incremental distress equation for concrete pavements: an application to model transverse joint faulting (in Spanish).Revista Ingeniería de Construcción, 17(3) 151-160.

Chon B.J. \& Lee S.W.(2007) Effects of uncracked joints in jointed concrete pavements. KSCE Journal of Civil Engineering. 11(3) 141-144.

Covarrubias J.P. (2012) Design of concrete pavement with optimized slab geometry. Revista Ingeniería de Construcción, 27 (3) 181 - 197.

Davids W.G. \& Mahoney J.P. (1999) Experimental Verification of Rigid Pavement Joint Load Transfer Modelling with EverFE. Transportation Research Record 1684, 81-89.

Hall K.A. (2009) Performance of Sealed and Unsealed Concrete Pavement Joints (TechBrief FHWA-HIF-09-013).

Hansen W. \& Jensen E.A. (2001) Transverse Crack Propagation of JPCP as Related to PCC Toughness (Report RC-1404).

Houben, L.J.M. (2010) Model for Transversal Cracking in Non-Jointed Plain Concrete Pavements as a Function of the Temperature Variations and the Time of Construction. Proceedings of the 7th International DUT-Workshop on Design and Performance of Sustainable and Durable Concrete Pavement, Sevilla, Spain.

Houben, L.J.M. (2010) Transversal Cracking in Jointed Plain Concrete Pavements for Dutch Climatic Conditions. Proceedings of the 7th International DUT-Workshop on Design and Performance of Sustainable and Durable Concrete Pavement, Sevilla, Spain.

Jung Y.S., Neshvadian K. \& Zollinger D. (2011) Seal No Seal. Workshop of Seal No Seal Program, Utah, U.S.A.

Lee, S. and Stoffels, S. (2003). Effects of Excessive Pavement Joint Opening and Freezing on Sealants. Journal of Transportation Engineering, 129(4), 444-450.

Lee S.W. (2003).A probabilistic model for joint-movements in jointed concrete pavements. KSCE Journal of Civil Engineering, 7(2) 141-146.

NCHRP (2004). Guide for Mechanistic-Empirical Design of New and Rehabilitated Pavement Structures, Part 3-Design Analysis. Transportation Research Board.

Pradena M.A. \& Houben L.J.M. (2014) Sustainable Pavements: An Analysis of the Crack Width in Jointed Plain Concrete Pavements with Short Slabs. Proceedings of the 14th International GeoConference on Nano, Bio and Green Technologies for a Sustainable Future, Varna, Bulgaria.

Pradena M.A. \& Houben L.J.M. (2014) Sustainable Pavements: Influence of the Saw-Cutting Method on the Performance of JPCP. Proceedings of the 14th International GeoConference on Nano, Bio and Green Technologies for a Sustainable Future, Varna, Bulgaria.

Pradena M.A. \& Houben L.J.M. (2014) Effects of the joint-uncracking phenomenon upon the users of urban jointed plain concrete pavements. Proceedings of the International Multidisciplinary Scientific Conference on Social Sciences and Arts - Section Architecture and Design, Varna, Bulgaria.

Pradena M.A. \& Houben L.J.M. (2015) Analysis of stress relaxation in jointed plain concrete pavements. Baltic Journal of Road and Bridge Engineering, 10(1), 46-53.

Pradena M.A. \& Houben L.J.M. (2015) Cost-effective joint configurations of concrete pavements for a sustainable infrastructure. Journal of Transport Literature, 9(2), 45-49.

Roesler J.R. (2013) Thinner Concrete Pavement Technologies. Meetings of the National Concrete Pavement Technology Center, Philadelphia, U.S.A.

Shober S.F. (1987) Are pavement joint sealants always necessary?. (Publication \#C870289).

Yu H.T., Darter M.I., Smith K.D., Jiang J. and Khazanovich L. (1996). Performance of concrete Pavements Volume III - Improving Concrete Pavement Performance. Final Report (DTFH61-91-C-0053). 